\title{
Cone-beam and micro-computed tomography for the assessment of root canal morphology: a systematic review
}

\section{Caroline Cristina BORGES(a) (iD \\ Carlos ESTRELA ${ }^{(b)}$ iD \\ Daniel de Almeida DECURCIO(b) ID \\ Jesus Djalma PÉCORA ${ }^{(a)}$ \\ Manoel Damião \\ SOUSA-NETO(a) ID \\ Giampiero ROSSI-FEDELE(c)}

(a) Universidade de São Paulo - USP, School of Dentistry of Ribeirão Preto, Department of Restorative Dentistry, Ribeirão Preto, SP, Brazil.

(b) Universidade Federal de Goiás - UFG, Faculty of Dentistry, Department of Stomatological Sciences, Goiânia, Brazil.

(c) University of Adelaide, Adelaide Dental School, Adelaide, Australia.

Declaration of Interests: The authors certify that they have no commercial or associative interest that represents a conflict of interest in connection with the manuscript.

Corresponding Author:

Daniel de Almeida Decurcio

E-mail:danieldecurcio@gmail.com

Submitted: February 2, 2020

Accepted for publication: April 14, 2020

Last revision: April 22, 2020
Abstract: This study presents an overview of the accuracy of cone beam computed tomography (CBCT) compared with micro-computed tomography $(\mu \mathrm{CT})$ in the assessment of root canal morphology of extracted human permanent teeth. A database search in PubMed, PubMed Central, Embase, Scopus, Opengrey, Scielo and Virtual Health Library was conducted which compared root canal morphology of extracted human permanent teeth on the accuracy of CBCT with $\mu \mathrm{CT}$. In accordance with PRISMA statement guidelines, data were extracted on study characteristics, target mediators, sampling and assay techniques and the parameters associated with obtaining the image and ability to identify the root canal morphology. Amongst 2734 records, ten fulfilled the inclusion criteria. Four studies compared the accuracy of CBCT and $\mu \mathrm{CT}$ in the assessment of root canal morphology using Vertucci's classification, with at least one CBCT group or subgroup of each study presented high agreement compared to the $\mu \mathrm{CT}$. Six studies assessed more detailed root canal morphology, including two articles that found a lack of agreement between these imaging systems. Risk of bias was deemed low in three studies, moderate in four and high in three. CBCT can be as accurate as $\mu \mathrm{CT}$ in the assessment of several morphological features of extracted human permanent teeth; however there are some exceptions related to the more detailed morphological aspects. Voxel size likely influences the ability to detect these features, though the different aspects of exposure setting used in studies components may be confounding factors. CBCT may be considered for the assessment of root canal morphology ex-vivo.

Keywords: Cone-Beam Computed Tomography; X-Ray Microtomography; Dental Pulp Cavity.

\section{Introduction}

The morphology of the root canal system is possibly one of the main confounding factors in ex vivo studies in Endodontology. In-vitro studies aim to have strictly controlled conditions, including limiting the heterogeneity of samples used for the assays. In fact, study results may be influenced by the effect of the morphological variations of the root canal system instead of the element of interest. ${ }^{1,2}$ Two-dimensional radiography is commonly used as the method for sample selection in endodontic research., ${ }^{3,4}$ However, this 
method presents with limited accuracy by providing two-dimensional images of what, in reality, is a threedimensional structure. ${ }^{2,6}$

Micro-computed tomography $(\mu \mathrm{CT})$ has been popular in recent years in studies of hard tissues in general. In Endodontology, in particular, it has been used to document the internal and external morphologies of teeth ${ }^{7,8,9}$ amongst others. $\mu \mathrm{CT}$ has been used as a reference standard in several root canal morphology studies. ${ }^{10,11} \mu \mathrm{CT}$ has the advantages of being a reproducible, non-invasive and non-destructive technique.

Similarly, cone beam computed tomography (CBCT) is frequently used for the identification of root canal morphology. ${ }^{8,9,12,13} \mathrm{CBCT}$ overcomes some of the disadvantages of $\mu \mathrm{CT}$ such as scan time, radiation dosage and high cost, as well as widespread use in clinical practice, therefore, it has also been used in laboratory assays.

However, previous studies suggest that CBCT could fail to detect some minute morphological features, such as of accessory canals ${ }^{14}$ and be inadequate for the assessment and identification of particular types of root canal morphology. ${ }^{15,16}$ Therefore, it can be expected that $\mathrm{CBCT}$ and $\mu \mathrm{CT}$ imaging does not yield comparable values for root canal morphologic quality parameters, as the latter has superior image sharpness, amongst others.

Recently, the development of specific software and programs for the interactive visualisation of CBCT datasets has allowed the evaluation of the entire volume of the scanned structure, as well as axial, sagittal and coronal bi-dimensional sections simultaneously. ${ }^{8,17,18,19,20,21}$ Furthermore, CBCT is of relatively easier access for many investigators.

Due to the technological innovations in CBCT imaging, we must consider the following question: can CBCT images be used to assess root canal morphology ex-vivo, instead of $\mu \mathrm{CT}$ ? Is It might be possible to obtain root canal morphology measurements for CBCT images which can be equivalent to $\mu \mathrm{CT}$ with lower scanning time and lower cost for image acquisition and easier access? Thus, the accuracy of $\mathrm{CBCT}$ and $\mu \mathrm{CT}$ in the assessment of root canal morphology of extracted human permanent teeth should be compared. The question under review was framed according to the PICO format (Population; Intervention; Comparison; Outcome): P: extracted human permanent teeth; I: imaging using CBCT; $\mathrm{C}$ : imaging using $\mu \mathrm{CT} ; \mathrm{O}$ : accuracy to identify/detect morphological features.

The question under review was framed according: Is $\mathrm{CBCT}$ as accurate as $\mu \mathrm{CT}$ in the assessment of root canal morphology of extracted human permanent teeth?

\section{Methodology}

This systematic review followed the Preferred Reporting Items for Systematic Reviews and Meta-Analysis (PRISMA) statement guidelines. ${ }^{22}$

\section{Preregistration}

A protocol was preregistered with the International Prospective Register of Systematic Reviews (PROSPERO) on the 20th of July 2018 (record number: CRD42019123288).

\section{Data Collection}

The following databases used were PubMed, PubMed Central (PMC), Embase, Scopus, Opengrey, Scielo and Virtual Health Library (VHL) with combinations of the following terms: [CBCT*] OR [Cone Beam computed Tomography*] OR [micro-CT*] OR [x-ray microtomography] OR [micro ct] AND [anatomy root canal*] OR [root canal*] OR [morphology root canal*]. The Endnote software (Thompson Reuters, Toronto, Canada) was used to manage research data and eliminate duplicated publications. There were no restrictions placed on the year of publication. Final database search was completed on the 5 th of December 2018.

The inclusion criteria used in the systematic review were as follows:

a. Publication in English or other Latin alphabets;

b. Extracted permanent human teeth;

c. Absence of root canal instrumentation or other root canal treatment procedures;

d. Root canal morphology assessment using CBCT and $\mu \mathrm{CT}$;

e. Root canal morphology assessment as the outcome. Studies were excluded when they assessed pathological variations (e.g. dental resorption) or 
when they were case report/series, review articles or expert opinion, or when the above inclusion criteria were not met.

Additional articles of potential relevance from the bibliography of included articles were subjected to the same inclusion/exclusion criteria. Authors of the included studies were contacted for clarification or requested to provide further information as needed.

\section{Evaluation of the selected studies}

The titles and abstracts of the articles were analyzed by two independent reviewers (CCB and GRF), taking into consideration the inclusion and exclusion criteria established for this review. In case of disagreement regarding inclusion and exclusion of a retrieved article, the consensus was reached by a discussion between reviewers. The description of the study methodology was retrieved and summarised from the included articles by two reviewers (CCB and GRF) to allow comparison amongst studies.

The following information was extracted for each study and recorded on a data collection sheet: author(s), year of publication, journal, country, study, tooth type, imaging and described settings by methods and compared morphological outcomes.

The studies were evaluated according to their experimental quality by two independent reviewers (CCB, GRF) based on a modified version of a previously published risk of bias assessment tool. ${ }^{22}$ The assessment included the following:

a. Sample size calculation (Adequate: yes; Unclear: not specified; Inadequate: no);

b. The comprehensiveness of exposure settings reporting (Adequate: yes; Unclear: not specified; Inadequate: no). Various factors may interfere with the final result of the image quality as voxel size, dynamic image range, $x$-ray parameters Kilovoltage and Milliamperage, native acquisition, the field of view (FOV), software and scanner calibration and the software itself. ${ }^{20}$ The studies were considered adequate - when they depicted parameters such as Kilovoltage, Milliamperage and FOV values corresponding to CBCTs, not specified - when it did not present one of these parameters and inadequate - when the field of view and voxel size were inadequate. c. Sufficient description of outcomes (Adequate: yes; Unclear: not specified; Inadequate: no); Blinding of outcome assessment [Examiner(s) concealment of allocation (Adequate: yes; Unclear: not specified; Inadequate: no)];

d. Observer(s) reliability assessment (Adequate: yes; Unclear: not specified; Inadequate: no);

e. Attrition bias [Sample loss reported] (Adequate: yes; Unclear: not specified; Inadequate: no). To synthesize the validity of studies, they were classified into the following categories:

f. Low risk of bias (i.e. studies that met at least four of the quality criteria);

g. Moderate risk of bias (i.e. studies that met between two and four of the quality criteria);

h. High risk of bias (i.e. studies that met at less than two of the quality criteria). Disagreements concerning study scores were discussed until a decision was obtained by consensus.

\section{Results}

The database search strategy yielded in a total of 2734 publications after the removal of duplicates. Amongst the 2734 studies, ten satisfied the inclusion criteria ${ }^{9,18,23,24,25,26,27,28,29,30}$ and ten were excluded, nine have different object of study $24,31,32,33,34,35,36,37,38$ and one study has absence of comparative analysis. ${ }^{14}$ The results of the search strategy are represented in Figure 1 , while the information extracted for each study is presented in Tables 1 and 2. $\mu \mathrm{CT}$ was considered as the reference in all component studies. The authors of six studies ${ }^{23,25,26,27,29,30}$ were contacted for clarification of the imaging exposure setting, as this was not able to be determined by the data presented in the studies, without reply.

Main features of the component studies are presented in Table 1. Root canal configuration using Vertucci's classification was assessed in four articles. ${ }^{25,26,28,29}$ These component studies included 293 teeth in total, including maxillary and mandibular first molars and mandibular incisors. Among this subgroup, at least one CBCT group or subgroup of each study presented high agreement compared to $\mu \mathrm{CT}$. This included assessment of mesiobuccal canals, ${ }^{26}$ anatomic patterns of 


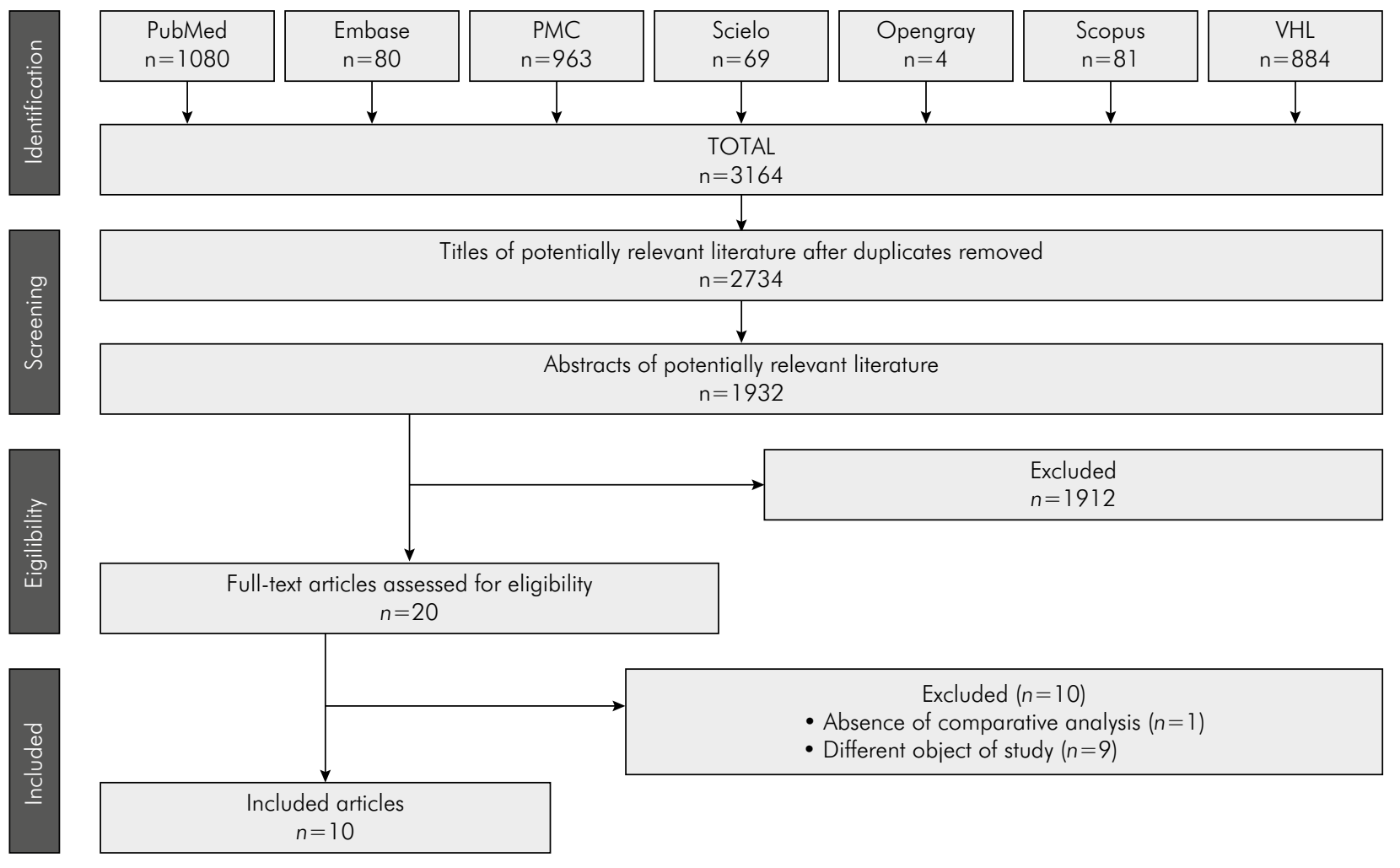

Figure 1.Flowchart of the methodology.

Table 1. Main characteristics of the included studies: sample characteristics.

\begin{tabular}{|c|c|c|c|c|}
\hline Study & Tooth type & $\begin{array}{l}\text { Number } \\
\text { of teeth }\end{array}$ & General feature assessment & Specific feature assessment \\
\hline Domark et al. $(2013)^{23}$ & $\begin{array}{l}\text { First/second maxillary } \\
\text { molars }\end{array}$ & 27 & Detailed morphologic characteristics & $\begin{array}{l}\text { Number of root in the mesiobuccal } \\
\text { root of maxillary molar }\end{array}$ \\
\hline Marca et al. $(2013)^{24}$ & Maxillary premolars & 16 & Detailed morphologic characteristics & Root and canal areas \\
\hline Freitas et al. $(2014)^{26}$ & First maxillary molars & 35 & $\begin{array}{c}\text { Assessment of root canal configurations } \\
\text { using Vertucci's classification }\end{array}$ & Type of anatomy of MB canal \\
\hline Fernandes et al. $(2014)^{25}$ & Mandibular incisors & 40 & $\begin{array}{c}\text { Assessment of root canal configurations } \\
\text { using Vertucci's classification }\end{array}$ & $\begin{array}{l}\text { Various anatomic patterns of } \\
\text { mandibular incisor }\end{array}$ \\
\hline $\begin{array}{l}\text { Ordinola-Zapata et al. } \\
(2017)^{28}\end{array}$ & $\begin{array}{l}\text { Mandibular first } \\
\text { molars }\end{array}$ & 75 & $\begin{array}{l}\text { Assessment of root canal configurations } \\
\text { using Vertucci's classification }\end{array}$ & $\begin{array}{l}\text { Configuration of the mesial root } \\
\text { (Type I and II) }\end{array}$ \\
\hline Zhang et al. $(2017)^{29}$ & $\begin{array}{l}\text { Mandibular first } \\
\text { premolars }\end{array}$ & 143 & $\begin{array}{c}\text { Assessment of root canal configurations } \\
\text { using Vertucci's classification }\end{array}$ & $\begin{array}{l}\text { Root canal configuration } \\
\text { of premolars }\end{array}$ \\
\hline Shaheen et al. $(2017)^{18}$ & Mandibular premolars & 24 & Detailed morphologic characteristics & Volume \\
\hline Michetti et al. $(2017)^{27}$ & $\begin{array}{l}\text { Incisors/maxillary molar/ } \\
\text { mandibular molars }\end{array}$ & 3 & Detailed morphologic characteristics & Canal area and the Feret's diameter \\
\hline Rashed et al. $(2018)^{30}$ & Maxillary premolars & 10 & Detailed morphologic characteristics & $\begin{array}{c}\text { Pulp horn/pulp chamber, isthmus, } \\
\text { number of canals, lateral canals } \\
\text { and remaining dentin thickness of } \\
\text { maxillary premolars }\end{array}$ \\
\hline Tolentino et al. $(2018)^{9}$ & Mandibular first molars & 40 & Detailed morphologic characteristics & Detect and measure isthmi \\
\hline
\end{tabular}




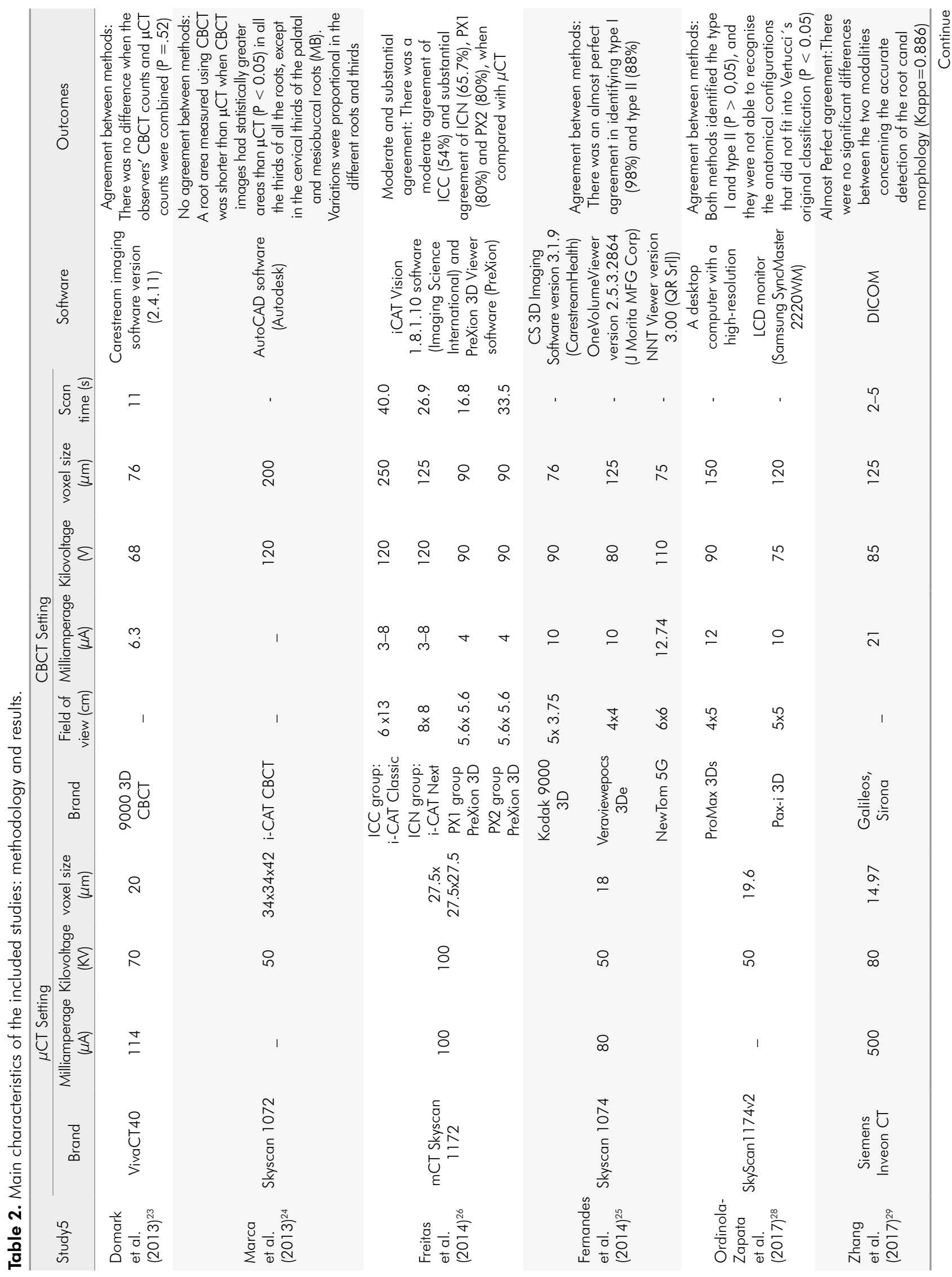




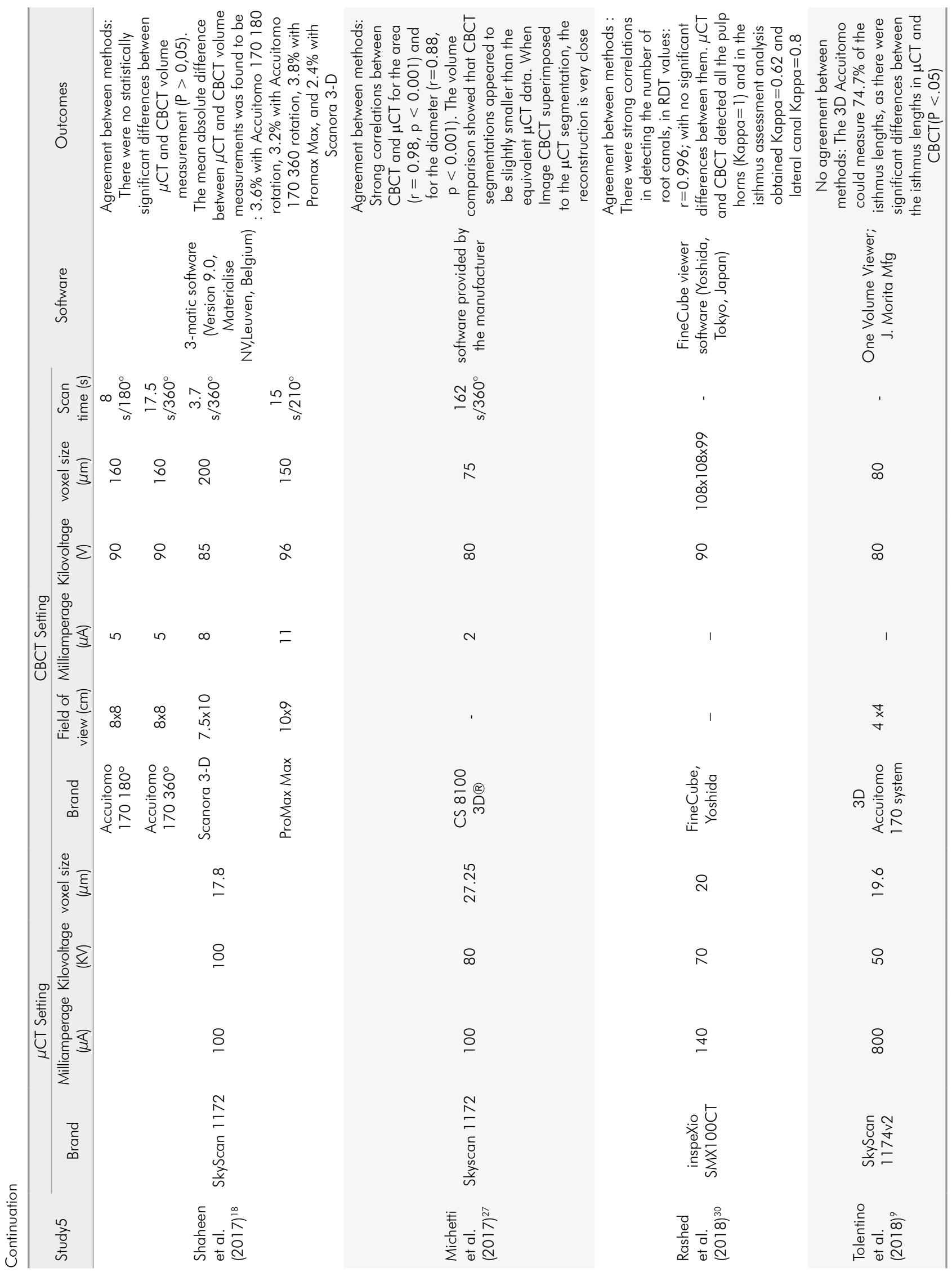


mandibular incisors, ${ }^{21}$ the configuration of the mesial root of mandibular first molars ${ }^{25}$ and root canal configuration of premolars. ${ }^{29}$

The remaining six studies evaluated more detailed morphology of the root canal system. ${ }^{918,23,24,27,30}$ These included 120 teeth in total. Two articles including 56 teeth found lack of agreement when detecting and measuring isthmi or assessing root and canal areas. ${ }^{9,24}$ Four studies with 64 teeth showed evidence of the agreement between these methods when evaluating the number of canals in mesiobuccal roots of maxillary molars as well as canal area and volume. ${ }^{18,23,27,30}$

Imaging apparatus and methods, together with outcome measurement techniques are reported in Table 2. A broad variability in equipment settings, software and outcome measures was evident amongst the component studies.

Due to the variety of methods and parameters used to measure the morphological outcomes, it was not possible to standardize the research data and perform a meta-analysis. Therefore, in the present systematic review, a narrative synthesis was carried out, ${ }^{39}$ after collating the data and tabulating the relevant results from the component studies.
Of the ten studies included, three presented a high risk of bias, ${ }^{24,29,27}$ four showed a moderate risk of bias $9,18,23,30$ and three had a low risk of bias ${ }^{26,25,28}$ (Figures 2 and 3).

\section{Discussion}

Eight out of ten component studies suggest comparable accuracy between the imaging techniques tested, at least with one of the CBCT devices compared. Disagreement these occurred for the assessment of more detailed morphology, such as measurement of isthmi ${ }^{9}$ and canal area. ${ }^{24}$ Therefore, several CBCT scanners, when using specific imaging modes, have a comparable accuracy for the assessment of endodontic morphology as $\mu \mathrm{CT}$.

In analyzing the different results, it must be considered that numerous factors may influence the final image quality and, consequently, in the evaluation of the data. These include the apparatus, the exposure setting, the software used to reconstruct and display the datasets, the monitor and, understandably the observer. ${ }^{20}$ These considerations are valid for both the $\mu \mathrm{CT}$ and $\mathrm{CBCT}$ imaging processes.

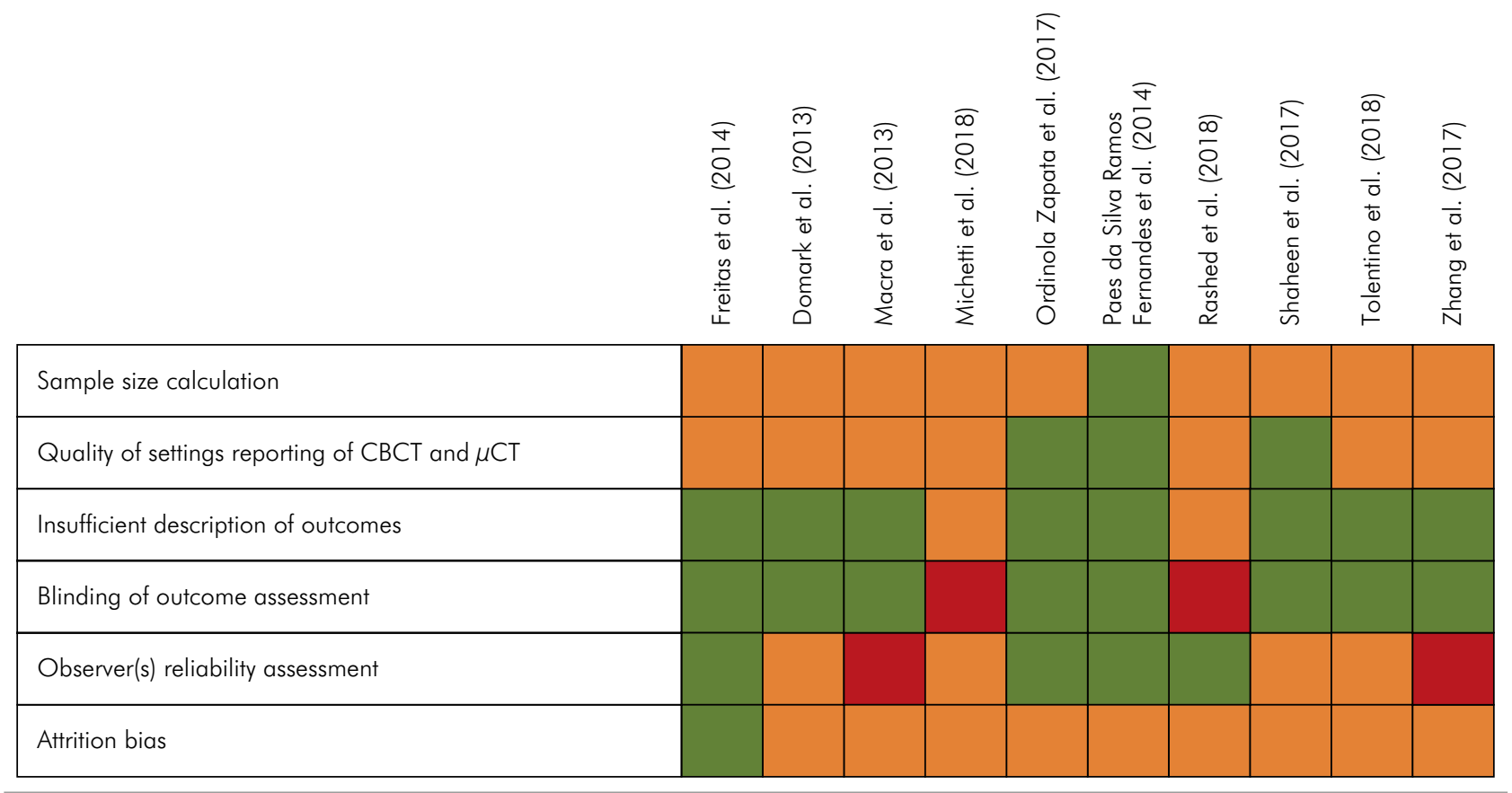

Figure 2. Risk of bias graph: Reviewers' judgements about each risk of bias item presented across all included studies. 


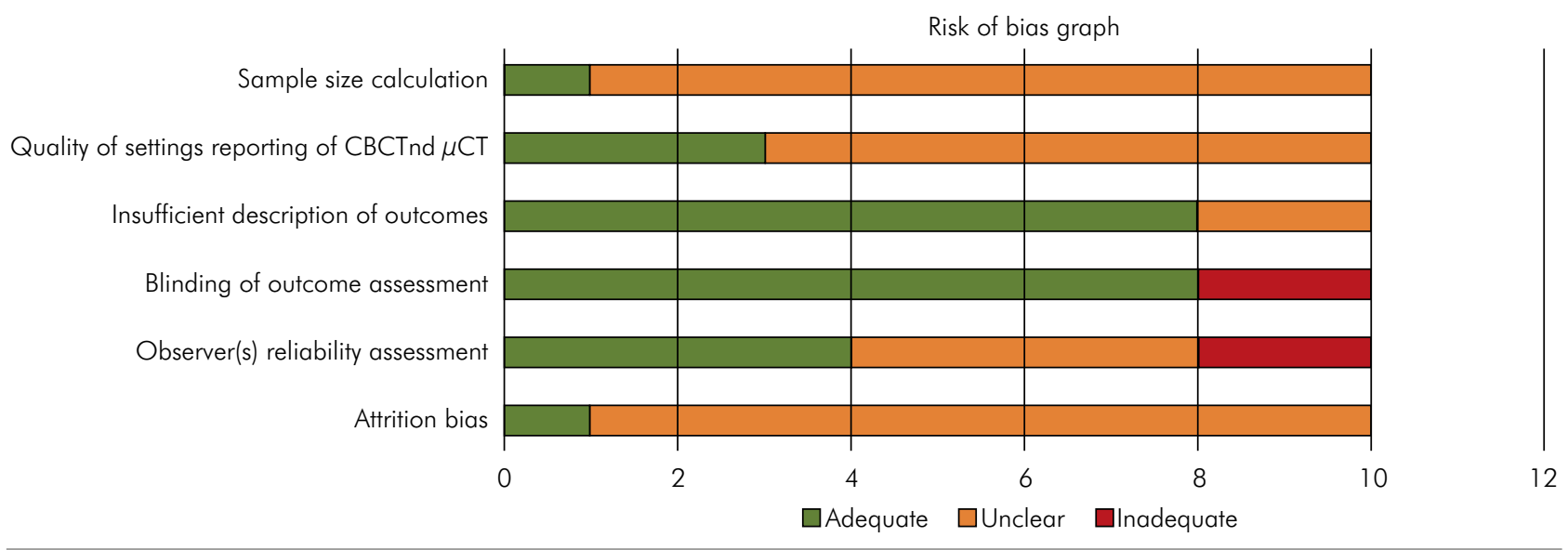

Figure 3. Risk of bias graph: Reviewers' judgements about each risk of bias item presented across all included studies.

The findings of the two imaging techniques concurred for the assessment of the number of canals and type of anatomy in mesiobuccal roots of maxillary molars, ${ }^{23,26}$ anatomic configuration of mandibular incisors ${ }^{25}$ and mandibular first premolars, ${ }^{18,29}$ the number of root canals, remaining dentin thickness, pulp horn detection, presence of the isthmi and lateral canals of premolars, ${ }^{30}$ plus canal area of incisors, maxillary and mandibular molars. ${ }^{27,28}$ Interestingly, agreement for Vertucci's configurations was found, but not for the proposed, more detailed, sub-classifications. ${ }^{28}$

When assessing quantitatively and qualitatively small structures, such as the root canal systems, high-definition images, the milliamperage must be taken into account. ${ }^{40}$ Tolentino et al., ${ }^{9}$ in spite of the used of parameters of the CTC and $\mu \mathrm{CT}$ similar to other studies, reported the highest value of milliamperage $\mu \mathrm{CT}$, which influences the quality of the reference images ${ }^{42,43}$ with higher values decreasing the image noise by increasing the signal at the detector. ${ }^{41}$

High tube potential has been associated with fewer volumetric distortion artefacts in CBCT scanning. ${ }^{43,44}$ However, among the two studies that used higher $\mathrm{kV}$ values, Marca et al. ${ }^{24}$ found CBCT to be inaccurate in detecting morphological features, whereas de Freitas et al. ${ }^{26}$ found moderate and substantial agreement amongst the two imaging modalities. Due to the limited detail related to the exposure setting of both imaging techniques setting, it was not possible to obtain robust conclusions regarding the effect of tube potential on the outcome.

Beam collimation restricts the radiation exposure to the region of interest, aiming that an optimal FOV is chosen depending on the area under investigation. Smaller scan volumes usually provide higher resolution images ${ }^{45}$ with enhanced root canal morphology visualization. ${ }^{46,47,48}$ Amongst the ten component studies, five did not report the field of view values, and of those reported they ranged from $4 \times 4$ to $10 \times 9$ $\mathrm{cm}$. Tolentino et al. ${ }^{9}$ used a small field of view $(4 \times 4$ $\mathrm{cm}$ ) and showed no agreement between CBCT and $\mu \mathrm{CT}$. Conversely, de Freitas et al., ${ }^{26}$ when using Prexion 3D for the diagnosis of MB canal with the same FOV, reported high agreement between imaging methods. Therefore, we are unable to present a definite conclusion of the effect of FOV per se for the specific setting and study designs.

No study compared different imaging software programs; therefore, we are unable to present a conclusion on this aspect. Two studies ${ }^{23,25}$ used the same software, with all eight remaining studies using diverse software programs. The software used for reconstruction may influence the image through general software design, image editing design, dynamic image range, sharpness of noise and margin size controls, artefact reduction, functional 3D (multi-way browser), multidirectional browser, compression with or without lost data logging, oblique coordinate logging, registration of filter settings for 
replication, as well as specific search tools. ${ }^{20}$ The capture, processing and reconstruction of $3 \mathrm{D}$ images are essential steps to obtain good quality images and to prevent artefacts. ${ }^{20,41,44}$ In order to overcome the limitations of the CBCT, Bueno et al. ${ }^{21}$ have shown the potential of new CBCT software with highquality images, for the visualization of complex anatomical structures and reduction of artefacts. Therefore, technological innovations supported by three-dimensional CBCT analysis have resulted in a considerable revolution, which has highlighted the need to review some previously-established concepts based on conventional imaging methods.

Four articles recorded that the professionals responsible for interpreting the data were endodontists, ${ }^{23,25,26,29}$ one a radiologist, ${ }^{9}$ and the remaining five studies did not mention the credentials and/or qualifications of the observers. ${ }^{18,24,27,28,30}$ Five out of ten components studies assessed intra- and inter-examiner agreement, which is of relevance considering that reliability is a concern in the study where the data is collected by observers. ${ }^{49}$ Domark et al. ${ }^{23}$ used the Friedman test, and the remaining four studies used Kappa statistics. ${ }^{25,26,29,30}$ All five studies showed substantial and almost perfect intra- and inter-examiner statistics agreement, thus reducing the amount of variability in how they view and interpret data and record it on the data collection instruments.

The main limitation of the present systematic review is the extensive methodological variation regarding the exposure settings; thus, it was not possible to compare the effect of the different aspect related to this on the assessment of root canal morphology of extracted teeth, and therefore propose robust conclusion on these aspects. Similarly, the diversity of the morphology assessed made comparison unattainable.

Since CBCT is commonly used in the specialist practice setting, ${ }^{50-55}$ the use of this imaging technique may simplify the understanding of endodontic morphology. However, the use of CBCT for the assessment of root morphology in-vivo requires further investigation, and variations should be taken into account as part of treatment planning. Similarly, ex-vivo studies should address this likely confounding factor at the design stage.

\section{Conclusion}

The present systematic review suggests that CBCT is as accurate as $\mu \mathrm{CT}$ in the assessment of several morphological features of extracted human permanent teeth, however, there are some exceptions related to the more detailed morphological aspects.

\section{Acknowledgement}

We thank Capes Foundation (Ministry of Education of Brazil, Brasília/DF, Brazil) for granting a scholarship to Caroline Cristina Borges. We also would like to thank Dr. Mike dos Reis Bueno for his important contribution to CBCT knowledge.

\section{References}

1. De-Deus G. Research that matters: root canal filling and leakage studies. Int Endod J. 2012 Dec;45(12):1063-4. https://doi.org/10.1111/j.1365-2591.2012.02104.x

2. Hartmann RC, Peters OA, Figueiredo JA, Rossi-Fedele G. Association of manual or engine-driven glide path preparation with canal centring and apical transportation: a systematic review. Int Endod J. 2018 Nov;51(11):1239-52. https://doi.org/10.1111/iej.12943

3. Cui Z, Wei Z, Du M, Yan P, Jiang H. Shaping ability of Protaper next compared with Waveone in late-model three-dimensional printed teeth. BMC Oral Health. 2018 June;18(1):115. https://doi.org/10.1186/s12903-018-0573-8

4. Stringheta CP, Bueno CE, Kato AS, Freire LG, Iglecias EF, Santos M, et al. Micro-computed tomographic evaluation of the shaping ability of four instrumentation systems in curved root canals. Int Endod J. 2019 Jun;52(6):908-16. Available from: https://doi.org/doi:10.1177/0300060518757607 https://doi.org/10.1111/iej.13084

5. Bürklein S, Flüch S, Schäfer E. Shaping ability of reciprocating single-file systems in severely curved canals: WaveOne and Reciproc versus WaveOne Gold and Reciproc blue. Odontology. 2019 Jan;107(1):96-102. https://doi.org/10.1007/s10266-018-0364-3

6. Estrela C, Bueno MR, Leles CR, Azevedo B, Azevedo JR. Accuracy of cone beam computed tomography and panoramic and periapical radiography for detection of apical periodontitis. J Endod. 2008 Mar;34(3):273-9. https://doi.org/10.1016/i.joen.2007.11.023 
7. Boschetti E, Silva-Sousa YT, Mazzi-Chaves JF, Leoni GB, Versiani MA, Pécora JD, et al. Micro-CT Evaluation of Root and Canal Morphology of Mandibular First Premolars with Radicular Grooves. Braz Dent J. 2017 Sep-Oct;28(5):597-603. https://doi.org/10.1590/0103-6440201601784

8. Estrela C, Couto GS, Bueno MR, Bueno KG, Estrela LR, Porto OC, et al. Apical foramen position in relation to proximal root surfaces of human permanent teeth determined by using a new cone-beam computed tomographic software. J Endod. 2018 Nov;44(11):1741-8. https://doi.org/10.1016/j.joen.2018.07.028

9. Tolentino ES, Amoroso-Silva PA, Alcalde MP, Honório HM, Iwaki LC, Rubira-Bullen IR, et al. Accuracy of high-resolution small-volume cone-beam computed tomography in detecting complex anatomy of the apical isthmi: ex vivo analysis. J Endod. 2018 Dec;44(12):1862-6. https://doi.org/10.1016/i.joen.2018.08.015

10. Park JW, Lee JK, Ha BH, Choi JH, Perinpanayagam H. Three-dimensional analysis of maxillary first molar mesiobuccal root canal configuration and curvature using micro-computed tomography. Oral Surg Oral Med Oral Pathol Oral Radiol Endod. 2009 Sep;108(3):437-42. https://doi.org/10.1016/i.tripleo.2009.01.022

11. Liu N, LiX, Liu N, Ye L, An J, Nie X, et al. A micro-computed tomography study of the root canal morphology of the mandibular first premolar in a population from southwestern China. Clin Oral Investig. 2013 Apr;17(3):999-1007. https://doi.org/10.1007/s00784-012-0778-1

12. Estrela C, Rabelo LE, Souza JB, Alencar AH, Estrela CR, Sousa Neto MD, et al. Frequency of root canal isthmi in human permanent teeth determined by cone-beam computed tomography. J Endod. 2015 Sep;41(9):1535-9. https://doi.org/10.1016/i.joen.2015.05.016

13. Sagale AA, Ramugade MM, Ganga R. Endodontic management of mandibular second premolar with type IX canal configuration using cone-beam computed tomography as a diagnostic aid: a rare case report. Contemp Clin Dent. 2018 Jun;9(5 Suppl 1):S180-4. https://doi.org/10.4103/ccd.ccd_153_18

14. Acar B, Kamburoğlu K, Tatar I, Arıkan V, Çelik HH, Yüksel S, et al. Comparison of micro-computerized tomography and cone-beam computerized tomography in the detection of accessory canals in primary molars. Imaging Sci Dent. 2015 Dec;45(4):205-11. https:// https://doi.org/10.5624/isd.2015.45.4.205

15. Sousa TO, Haiter-Neto F, Nascimento EH, Peroni LV, Freitas DQ, Hassan B. Diagnostic accuracy of periapical radiography and cone-beam computed tomography in identifying root canal configuration of human premolars. J Endod 2017;43:1176. https://doi: 10.1016/i.joen.2017.02.021

16. Nascimento EH, Abrahão Elias MR, Vasconcelos VH, Haiter-Neto F, Mendonça EF, Sousa TO. Ex vivo detection of apical delta in premolars: a comparative study using periapical radiography, cone-beam computed tomography, and micro-computed tomography. J Endod. 2019 May;45(5):549-553. https://doi.org/10.1016/i.joen.2019.02.022

17. Oliveira MV, Santos AC, Paulo G, Campos PS, Santos J. Application of a newly developed software program for image quality assessment in cone-beam computed tomography. Imaging Sci Dent. 2017 Jun;47(2):75-86. https://doi.org/10.5624/isd.2017.47.2.75

18. Shaheen E, Khalil W, Ezeldeen M, Van de Casteele E, Sun Y, Politis C, et al. Accuracy of segmentation of tooth structures using 3 different CBCT machines. Oral Surg Oral Med Oral Pathol Oral Radiol. 2017 Jan;123(1):123-8. https://doi.org/10.1016/i.0000.2016.09.005

19. Gambarini G, Ropini P, Piasecki L, Costantini R, Carneiro E, Testarelli L, et al. A preliminary assessment of a new dedicated endodontic software for use with CBCT images to evaluate the canal complexity of mandibular molars. Int Endod J. 2018 Mar;51(3):259-68. https://doi.org/10.1111/iej.12845

20. Bueno MR, Estrela C, Azevedo BC, Diogenes A. Development of a new cone-beam computed tomography software for endodontic diagnosis. Braz Dent J. 2018 Nov-Dec;29(6):517-29. https://doi.org/10.1590/0103-6440201802455

21. Bueno MR, Estrela CR, Granjeiro JM, Sousa-Neto MD, Estrela C. Method to Determine the root canal anatomic dimension by using a new cone-beam computed tomography software. Braz Dent J. 2019 Jan-Feb;30(1):3-11. https://doi.org/10.1590/0103-6440201902462

22. Higgins DG, Sterne JA. Assessing risk of bias in included studies. In: Higgins SG, ed. Cochrane handbook for systematic reviews of interventions. Cochrane; 2011 [cited 2015 Sep 17]. Available from: http://handbook.cochrane.org

23. Domark JD, Hatton JF, Benison RP, Hildebolt CF. An ex vivo comparison of digital radiography and cone-beam and micro computed tomography in the detection of the number of canals in the mesiobuccal roots of maxillary molars. J Endod. 2013 Jul;39(7):901-5. https://doi.org/10.1016/i.joen.2013.01.010

24. Marca C, Dummer PM, Bryant S, Vier-Pelisser FV, Só MV, Fontanella V, et al. Three-rooted premolar analyzed by high-resolution and cone beam CT. Clin Oral Investig. 2013 Jul;17(6):1535-40. https://doi.org/10.1007/s00784-012-0839-5

25. Fernandes LMPSR, Rice D, Ordinola-Zapata R, Alvares Capelozza AL, Bramante CM, Jaramillo D, et al. Detection of various anatomic patterns of root canals in mandibular incisors using digital periapical radiography, 3 cone-beam computed tomographic scanners, and micro-computed tomographic imaging. J Endod. 2014 Jan;40(1):42-5. https://doi.org/10.1016/i.joen.2013.09.039

26. Freitas JV, Baratto-Filho F, Coelho BS, Tomazinho FS, Crozeta BM, Sousa Neto MD, et al. Efficacy of different cone-beam computed tomographic protocols in the identification of mesiobuccal canals of maxillary first molars: a tomographic and ex vivo study. J Endod. 2017 May;43(5):810-5. https://doi.org/10.1016/i.joen.2016.12.011

27. Michetti J, Basarab A, Diemer F, Kovame D. Comparison of an adaptive local thresholding method on CBCT and $\mu$ CT endodontic images. Phys Med Biol. 2017 Dec;63(1):015020. https://doi.org/10.1088/1361-6560/aa90ff 
Borges CC, Estrela C, Decurcio DA, Pécora JD, Sousa-Neto MD, Rossi-Fedele G

28. Ordinola-Zapata R, Bramante CM, Versiani MA, Moldauer BI, Topham G, Gutmann JL, et al. Comparative accuracy of the Clearing Technique, CBCT and Micro-CT methods in studying the mesial root canal configuration of mandibular first molars. Int Endod J. 2017 Jan;50(1):90-6. https://doi.org/10.1111/iej.12593

29. Zhang D, Chen J, Lan G, Li M, An J, Wen X, et al. The root canal morphology in mandibular first premolars: a comparative evaluation of cone-beam computed tomography and micro-computed tomography. Clin Oral Investig. 2017 May;21(4):1007-12. https://doi.org/10.1007/s00784-016-1852-x

30. Rashed B, lino Y, Komatsu K, Nishijo M, Hanada T, Ebihara A, et al. Evaluation of root canal anatomy of maxillary premolars using sweptsource optical coherence tomography in comparison with dental operating microscope and cone beam computed tomography. Photomed Laser Surg. 2018 Sep;36(9):487-92. https://doi.org/10.1089/pho.2017.4416

31. Al-Rawi B, Hassan B, Vandenberge B, Jacobs R. Accuracy assessment of three-dimensional surface reconstructions of teeth from cone beam computed tomography scans. J Oral Rehabil. 2010 May;37(5):352-8. https://doi.org/10.1111/j.1365-2842.2010.02065.x

32. Maret D, Molinier F, Braga J, Peters OA, Telmon N, Treil J, et al. Accuracy of $3 \mathrm{D}$ reconstructions based on cone beam computed tomography. J Dent Res. 2010 Dec;89(12):1465-9. https://doi.org/10.1177/0022034510378011

33. Wang Y, He S, Yu L, Li J, Chen S. Accuracy of volumetric measurement of teeth in vivo based on cone beam computer tomography. Orthod Craniofac Res. 2011 Nov;14(4):206-12. https://doi.org/10.1111/j.1601-6343.2011.01525.x

34. Maret D, Telmon N, Peters OA, Lepage B, Treil J, Inglèse JM, et al. Effect of voxel size on the accuracy of 3D reconstructions with cone beam CT. Dentomaxillofac Radiol. 2012 Dec;41(8):649-55. https://doi.org/10.1259/dmfr/81804525

35. Benyó B. Identification of dental root canals and their medial line from micro-CT and cone-beam CT records. Biomed Eng Online. 2012 Oct;11:81. https://https://doi.org/10.1186/1475-925X-11-81

36. Maret D, Peters OA, Galibourg A, Dumoncel J, Esclassan R, Kahn JL, et al. Comparison of the accuracy of 3-dimensional cone-beam computed tomography and micro-computed tomography reconstructions by using different voxel sizes. J Endod. 2014 Sep;40(9):1321-6. https://doi: 10.1016/i.joen.2014.04.014

37. Mirmohammadi H, Mahdi L, Partovi P, Khademi A, Shemesh H, Hassan B. Accuracy of Cone-beam Computed Tomography in the Detection of a Second Mesiobuccal Root Canal in Endodontically Treated Teeth: An Ex Vivo Study. J Endod. 2015 Oct;41(10):1678-81. https://doi.org/10.1016/j.joen.2015.06.011

38. Xu J, He J, Yang Q, Huang D, Zhou X, Peters OA, et al. Accuracy of cone-beam computed tomography in measuring dentin thickness and its potential of predicting the remaining dentin thickness after removing fractured instruments. J Endod. 2017 Sep;43(9):1522-1527. https://doi: 10.1016/j.joen.2017.03.041

39. Joanna Briggs Institute. Joanna Briggs Institute reviewers' manual. Adelaide: Joanna Briggs Institute; 2015.

40. Ballrick JW, Palomo JM, Ruch E, Amberman BD, Hans MG. Image distortion and spatial resolution of a commercially available cone-beam computed tomography machine. Am J Orthod Dentofacial Orthop. 2008 Oct;134(4):573-82. https://doi.org/10.1016/j.ajodo.2007.11.025

41. Pauwels R, Silkosessak O, Jacobs R, Bogaerts R, Bosmans H, Panmekiate S. A pragmatic approach to determine the optimal kVp in cone beam CT: balancing contrast-to-noise ratio and radiation dose. Dentomaxillofac Radiol. 2014;43(5):20140059. https://doi.org/10.1259/dmfr.20140059

42. Safi Y, Hosseinpour S, Aziz A, Bamedi M, Malekashtari M, Vasegh Z. Effect of amperage and field of view on detection of vertical root fractures in teeth with intracanal posts. Iran Endod J. 2016;11(3):202-7. https://doi.org/10.7508/iej.2016.03.011

43. Esmaeili F, Johari M, Haddadi P, Vatankhah M. Beam hardening artifacts: comparison between two cone beam computed tomography scanners. J Dent Res Dent Clin Dent Prospects. 2012;6(2):49-53. https://doi.org/10.5681/joddd.2012.011

44. Celikten B, Jacobs R, Vasconcelos KF, Huang Y, Nicolielo LF, Orhan K. Assessment of volumetric distortion artefact in filled root canals using different cone-beam computed tomographic devices. Journal of Endodontics. J Endod. 2017 Sep;43(9):1517-21. https://doi.org/10.1016/i.joen.2017.03.035

45. Venskutonis T, Plotino G, Juodzbalys G, Mickevičien $\mathrm{L}$. The importance of cone-beam computed tomography in the management of endodontic problems: a review of the literature. J Endod. 2014 Dec;40(12):1895-901. https://doi.org/10.1016/i.joen.2014.05.009

46. Matherne RP, Angelopoulos C, Kulild JC, Tira D. Use of cone-beam computed tomography to identify root canal systems in vitro. J Endod. 2008 Jan;34(1):87-9. https://doi.org/10.1016/i.joen.2007.10.016

47. Hatcher DC. Operational principles for cone-beam computed tomography. J Am Dent Assoc. 2010 Oct;141 Suppl 3:3S-6S. https://doi.org/10.14219/jada.archive.2010.0359

48. Hassan BA, Payam J, Juyanda B, van der Stelt P, Wesselink PR. Influence of scan setting selections on root canal visibility with cone beam CT. Dentomaxillofac Radiol. 2012 Dec;41(8):645-8. https://doi.org/10.1259/dmfr/27670911

49. McHugh ML. Interrater reliability: the kappa statistic. Biochem Med (Zagreb). 2012;22(3):276-82. https://doi.org/10.11613/BM.2012.031

50. Bueno MR, Estrela C, Figueiredo JA, Azevedo BC. Map-reading strategy to diagnose root perforations near metallic intracanal posts by using cone beam computed tomography. J Endod. 2011 Jan;37(1):85-90. https://doi.org/10.1016/i.joen.2010.08.006

51. Doğramacı EJ, Rossi-Fedele G, McDonald F. Clinical importance of incidental findings reported on small-volume dental cone beam computed tomography scans focused on impacted maxillary canine teeth. Oral Surg Oral Med Oral Pathol Oral Radiol. 2014 Dec;118(6):e205-9. https://doi.org/10.1016/i.oooo.2014.09.006 
- Cone-beam and micro-computed tomography for the assessment of root canal morphology: a systematic review

52. Doğramaci EJ, Sherriff M, Rossi-Fedele G, McDonald F. Location and severity of root resorption related to impacted maxillary canines: a cone beam computed tomography (CBCT) evaluation. Aust Orthod J. 2015 May;31(1):49-58. Available from: Https://www.researchgate. net/publication/279533664

53. Estrela C, Nunes CA, Guedes OA, Alencar AH, Estrela CR, Silva RG, et al. Study of Anatomical Relationship between Posterior Teeth and Maxillary Sinus Floor in a Subpopulation of the Brazilian Central Region Using Cone-Beam Computed Tomography - Part 2. Braz Dent J. 2016 Jan-Feb;27(1):9-15. https://doi.org/10.1590/0103-6440201600679

54. Salem D, Alshihri A, Arguello E, Jung RE, Mohmed HA, Friedland B. Volumetric analysis of allogenic and xenogenic bone substitutes used in maxillary sinus augmentations utilizing cone beam CT: a prospective randomized pilot study. Int J Oral Maxillofac Implants. 2019 Jul/Aug;34(4):920-26. https://doi.org/10.11607/jomi.7318

55. Sun L, Yuan L, Wang B, Zhang L, Shen G, Fang B. Changes of alveolar bone dehiscence and fenestration after augmented corticotomy-assisted orthodontic treatment: a CBCT evaluation. Prog Orthod. 2019 Feb;20(1):7. https://doi.org/10.1186/s40510-019-0259-z 